\title{
Physician Compensation, Accountability and Performance in Canada: Changing the Pas de Deux
}

\begin{abstract}
$\bullet$
INTRODUCTION

Terrence Sullivan

Guest Editor

Professor and Senior Fellow, Institute of Health Policy, Management and Evaluation

University of Toronto

Toronto, $\mathrm{ON}$

$\sim$

ABSTRACT

Physician bargaining with provincial governments has been a challenge in the provinces of Canada since the origins of medicare, when this bilateral negotiation first began in Saskatchewan and was eventually codified in the Canada Health Act. In recent years, the emergence of accountability for performance has become a central policy focus in advanced countries to raise the bar on the quality and value of physician services and their effective integration within the broader healthcare system. The challenge has been to create real accountability while balancing growth in physician incomes with fiscal capacity and affordability. This commentary reflects a rich variety of perspectives from our contributing authors. It also lays out a number of challenges and changes that may be required to strengthen the importance of accountability for fair payments within Canadian medicare.
\end{abstract}

IN THIS INTERESTING collection of commentaries, we take the intrepid road into physician accountability and performance in Canadian medicare. The lead paper by Marchildon and Sherar (2018) lays out several key challenges.
These include the historical cycle of spending compression of health transfers (which included physicians' income) in the early mid-nineties during a period of national and regional fiscal restraint and capping of 
incomes, followed by fairly rapid growth back to the original trajectory of spending that preceded the dip in the 1990s. In the history of Canadian medicare, there were two points in time when overall physician incomes declined: the early days following the introduction of medicare (1971-1979) and the fiscal compression of the early nineties (1991-1996) (Grant and Hurley 2013).

In 2017, overall healthcare spending grew by $3.9 \%$ to an estimated $\$ 242$ billion. Physician spending grew slightly less at $3.4 \%$, whereas spending on drugs grew by $4.2 \%$, outpacing physician spending. Direct payments to physicians represented $15.4 \%$ of total health spending in 2017 (CIHI 2017). But looking at income alone may miss the direct and powerful influence of physician behaviour on a broad spectrum of expenditures, wielding the tools of service delivery through the stroke of a pen and increasingly through order entry systems creating diagnostic and treatment orders. Marchildon and Sherar (2018) note that the CIHI cost-drivers study of 2011 estimated that physician decisions propelled total healthcare cost growth from 1998 to 2008 to slightly more than half. With the arrival of Choosing Wisely Canada and its emphasis on appropriate care and diagnostic choices, some constructive peer pressure has mounted among clinicians to take value seriously and only order tests and procedures that are necessary and cost-effective.

Although spending growth has increased significantly, overall performance on access to care, efficiency, equity and outcomes places Canadian healthcare in a poor position relative to our international peers according to the 2017 Commonwealth Fund Survey (Commonwealth Fund 2017), as noted by Marchildon and Sherar (2018) and referenced in some detail by Mintz (2018) in his commentary later in this issue.

\section{Challenges of the Pas de Deux}

Marchildon and Sherar (2018) lay out a series of useful ideas to strengthen accountability for both primary care and specialty care. They also highlight the legacy of the Saskatchewan agreement and the lock-in that often develops between medical associations and provincial political parties, creating an effective duopoly, or what might be characterized as a very challenging pas de deux. The pas de deux is made up, much like a negotiation, of a predictable sequence of steps: the entrée, the slow adagio, a solo variation for each dancer and then a coda or finish. The sequencing may vary with the provincial-medical association arrangement and circumstance, but the dance is mostly predictable.

\section{Linking quality to performance}

Laporte (2018), in her reflection on our theme of physician accountability and performance, makes clear that the challenges in physician bargaining are inextricably bound up with the behaviour of provincial governments and political actors interacting with organized medicine. Canadian physician fee negotiations are largely a political as opposed to a technical and managerial project and often have theatrical dimensions to them (Boyle 2017). Governments and the public have an interest in pursuing accountability for performance, population health, quality and safety, value for money and patient-centredness. These important accountabilities have proved to be hard measures to link directly to physician payments in the dynamic duopoly of doctors and governments negotiating wages together. As Laporte points out, the assumption that governments can easily regulate and innovate systems to manage physician incentives conjures up Adam Smith's "man of systems" (Smith 1795) who may wish to impose his economic system on others, without due attention to their preferences. 
The same Adam Smith in The Wealth of Nations (1776) characterized physicians as rent seekers, defined as increasing one's share of existing wealth without creating new wealth in the real economy. However, it is hardly fair in this century to suggest that physicians are rent seekers, as the profession does generate important research discoveries, commerce and value in the drug, device and public health marketplace not to mention the productive effect of appropriate treatment on the lives of others.

\section{Control through regulation}

Another characteristic of rent-seeking is the capture of regulatory agencies to create an effective monopoly while sometimes creating disadvantages for others. One sees this latter behaviour in some "old school" physicians' attitudes toward allied health professionals whose service might extend or replace the services of the physician at a lower cost. The physician "monopoly" as a group, however, has given birth to constrained access to entry for other professional groups in Canada and elsewhere when new allied professionals and extenders have been introduced. A prime example of this would be the painfully slow pace of growth of nurse practitioners (just over 2,500 in Canada in 2010 [CNA 2012]) despite the definitive Burlington randomized trial by Sackett and colleagues 44 years ago in 1974 (Sackett et al. 1974). The Burlington trial concluded that the quality of care provided by family physicians and nurse practitioners appeared to be similar, using a "quantitative indicator condition" approach. Despite high levels of satisfaction from patients, "the new method of primary care was not financially profitable to doctors because of current restrictions on reimbursement for the nursepractitioner services" (Spitzer et al. 1974).

The medical resistance to new entrants in the professional ranks has been fought regionally across Canada, from the introduction and exit of nurse anesthetists to the re-entry of anesthesia assistants to the challenges more recently faced by nurse sigmoidoscopists/ endoscopists and, more recently, physician assistants (CanadianPA.CA n.d.).

\section{The slide in the last 3-4 years may seed some interest in greener pastures, but there is no evidence of meaningful physician exits...}

\section{Impact of geography on wage harmonization}

Canada's geography includes the large undefended border with the US, a country that pays higher wages, with quite a different mix of well-paid specialty physicians dominating the smaller number of less well-paid primary care physicians. Canada, with a relatively even split of specialty care and primary care physicians totalling 84,260 in 2018 , is verging on negligible out-migration across this border, with 154 doctors leaving Canada in 2016 and 212 returning from abroad, amounting to a net gain (CIHI 2016; CMA 2018). There is currently no "out-migration" surge from Canada, and physician numbers have been growing steadily, outpacing general population growth in the last 10 years (CIHI 2016). But as Mintz (2018) rightly points out, our dollar has fallen dramatically with US tax reform, trade disputes, our commodity-dominant marketplace and the Bank of Canada's approach to interest hikes relative to our neighbour to the south. The slide in the last 3-4 years may seed some interest in greener pastures, but there is no evidence of meaningful physician exits, at least not yet.

Physicians must be paid "reasonable compensation" for all insured services as specified in the Canada Health Act. Each of the provinces, on slightly different cycles, enters 
into bargaining with provincial/territorial medical associations of different institutional configurations with the objective of getting fair agreements.

Going back to the earlier metaphor, there are at least three challenges in the pas de deux of government bargaining with physicians. The first is how to achieve a fair agreement without steadily inflating provincial spending beyond fiscal capacity. The second is how to ensure optimal quality, safety and value for money in the provision of physician services to patients, for which it must be said that the instruments to achieve this are emerging but not fully present as contingent reimbursement and public reporting processes today. The third is to ensure that there is some measure of reason and procedural fairness in how fees are compensated within and among physician practice type.

\section{Quebec's approach to governance}

Marchildon and Sherar (2018) highlight the challenges of pinning down physician incomes and performance in the absence of greater accountability for performance and governance practices. Several physician governance issues are well addressed in the commentary by Rosenberg (2018) from Montreal. Quebec has been the leader in regional integration dating back to the Castonguay-Nepveu report, which was codified in law in 1970. Many regional versions have been tried in Quebec and elsewhere in Canada. The current reform in Quebec abolished regional health authorities and instead created integrated hospital and local health and social service delivery networks responsible for population health within defined geographies. Rosenberg makes the case that modern care requires both the "solution shop" model of diagnosing and characterizing the problem and the second step in the process, which is the value-added work of doing an intervention effectively, affordably and conveniently. He argues that hospital solution shops need to be paid on a fee-for-service (FFS) basis and value-added activities should be paid routinely at a fixed price as they can largely guarantee their outcomes. He further suggests that payment structures should be reformed to reflect these two quite different types of work and consequently that they should be paid differently. He adds that the dominant payment structures (largely FFS) create a situation where the same service may be reimbursed differently depending on which specialist is billing.

Quebec has both a specialist negotiation and a primary care physician negotiation. Rosenberg notes that primary care practices in Quebec enter a contractual relationship with the ministry. The intent of Quebec's legislation Bill 10 has been to expand the role of family medicine in Quebec, with the regional authorities providing allied health professionals to family medicine groups to further integrate patient care and extend their capacity for different care trajectories. With Quebec intending to introduce an activity-based funding model for the delivery system, Rosenberg suggests that surgeons, who do different things differently, should be on salary, with a bundled payment for services that includes the physician salary, and should be paid through the hospital.

\section{The Promise of Accountable Primary Care}

Glazier and Kiran (2018) take on the challenge of primary care and system change. They agree that physicians display little accountability for managing system resources and that their decisions drive costs. They point out that their real accountability is to the patients for whom they provide care. Accountability to individual patients is certainly central to improving population 
health. They also point out, however, that not every patient has a primary care doctor, making it hard to align efforts, particularly with walk-in clinics and emergency rooms acting as the first stop for some hard-to-reach patients. They support a "tight rostering" model, which ensures total population coverage. They note that to ensure that patients are well informed, a single electronic health record should be accessible to patients and providers, bearing in mind that Ontario MD lists a dozen different certified EMR systems. Glazier and Kiran advocate sensible options to advance the role of health quality agencies and governments to ensure that primary care practice-level data are readily available and used to generate improvement - one form of accountability. They also agree on the need for physician autonomy but accept that some formal accountability at the physician group should be established with local health authorities, ministries and quality improvement organizations. Although some quality reporting for primary care is getting under way in several provinces, they argue that a bigger effort is required to spread and scale the reporting, which would almost certainly go a long way to raising physician and public accountability for quality of care.

\section{Experience in Alberta}

The Church, Skrypnek and Smith commentary (2018) also focuses on primary care reform to improve accountability. Alberta has long wished to shift away from FFS practices, with the promise of some greater efficiencies in primary care. Despite strong efforts dating back to 2003, Alberta spends more on family medicine than the Canadian average and has the fewest numbers of primary care doctors on alternate payment models. The earliest efforts to build primary care networks (PCNs) in Alberta began some years ago. PCNs submit three-year business plans to the government and work to review their progress with the provincial government. In 2014, Alberta introduced a primary care approach with the objective of ensuring that all Albertans should be attached to a primary care home with a focus on disease prevention. The current PCN committee is trying to advance a blended capitation model for family physicians, presumably to reduce dependence on FFS.

A good fraction of the Alberta PCNs have working patient panels. After-hours care remains an issue, as in other provinces, with approximately $50 \%$ of $\mathrm{PCN}$ s providing after hours coverage. A project called AIM Alberta is working to improve access management and improvement methods. Although few physicians have converted to alternate payment mechanisms, the push with PCNs does seem to be yielding better comparative performance in some areas, more integrated accountability and continuity of care with greater penetration of physicians in outlying areas.

McIntosh's (2018) commentary follows directly on the theme of trying to implicate Alberta physicians in the 2016 agreement to generate greater peer review and accountability mechanisms, including linking certain benefits and compensation increases to performance on other cost-saving measures. It remains unclear if the 2018 agreement will succeed in achieving the $\$ 500 \mathrm{M}$ targeted for savings in the earlier agreement. Although the optimism with which McIntosh discusses the agreement is laudable, it is still unclear what the outcomes will be in the current environment, where physicians have agreed to freeze fees. But if there are no restrictions on utilization growth, it will be hard to hold the pay freeze in place in a province where physician fees have grown at $9 \%$ until this last year. Price and quantity of fees (utilization) matter in the reimbursement discussion (Lomas et al. 1989). 
There was a time when Ontario firted with comprehensive health organizations in the north...

\section{Will current reforms really work?}

In his commentary, Mintz (2018) questions the wisdom of conventional primary care reforms, suggesting that more integrated structures be considered, including hospitals, clinics, primary care, home care and longterm health services - a kind of comprehensive health organization under one organizational roof (as is evolving steadily in Quebec) that would compete for patients. These structures would compete for resources, being rewarded by governments not just for enrolment but also for the quality of care provided. Failing organizations that attract fewer patients would be subject to takeover and replacement of leadership by governments, much like the Ontario institution of installing a "supervisor" to get back on the organizational rails. Mintz's integration notion is appealing, although it is a little at odds with the recent "elimination" of regional structures in Alberta, Saskatchewan and Nova Scotia. Moreover, in some of the far-flung parts of the country, little real competition is possible. There was a time when Ontario flirted with comprehensive health organizations in the north, which was documented in a series of papers that appeared in the second edition of Healthcare Papers (Leatt et al. 2000), but they were not designed for real competition, given the geography.

\section{Challenges in remote areas}

In her commentary, Chatwood (2018) underlines the challenging realities of recruiting and keeping physicians in a remote area of Canada, the Northwest Territories (NWT). NWT, with a $52 \%$ Indigenous population, faces significant challenges, with the population spread out over 33 communities, 17 of which have road access. The region is just completing a reform where eight former health authorities have amalgamated into a single territorial authority. Physician payment schemes in NWT were moved from FFS to salary in 2000 - a wise measure to ensure greater retention. The territorial medical association ensures that members have benefits such as parental leave, extended health coverage, CME and CMPA reimbursement, vacation, leave, retention bonuses and a pension plan. The NWT government has made a commitment to reconciliation, and this includes the greater use of traditional health and practices together with Western medicine. The region faces significant equity challenges and elusive responsibility for the health services provided by federal and provincial/territorial governments and those provided by Indigenous communities and their governments. Chatwood is optimistic that the current tripartite approach, if grounded in reconciliation, can help support the health services base for Indigenous communities and physician leaders.

\section{Increasing Transparency on Earnings and Revenues}

The final paper in the collection is an important and distinct contribution from Nielson and Sweetman (2018) focused on the changes in physician income associated with physicians who have incorporated and take income as Canadian-controlled private corporations (CCPCs). This thoughtful study indicates that physicians, like most other workers, respond to incentives. The authors point out that the challenges to improve physician integration into the governance structure of health services delivery are not small. The appetite of provincial governments to drive in this direction has been weak to the point noted in several of our commentaries that it is quite 
challenging to tell what physicians' take-home income looks like. The level of secrecy on physician incomes is gradually relaxing but inconsistently across the country. Ontario's Court of Appeal recently made clear that the disclosure of the highest billing physicians in Ontario is justifiable, potentially opening the door to full disclosure of income subject to the view of the current government and any possible further actions (Boyle 2018). Other provinces, including New Brunswick, British Columbia, Manitoba and Prince Edward Island, either release information on payments to doctors from the public purse or are considering doing so. It is perhaps noteworthy that the US began public disclosure of Medicare payments to doctors in 2014.

Nielson and Sweetman assembled the national data (less the territories) from the long-form census (1996, 2001 and 2006) and the National Household Survey (NHS) in 2011. They illustrate that physicians incorporate as CCPCs across Canada and have generated conservative estimates of the $4-5 \%$ revenues associated with incorporation. Their paper also illustrates the rapid growth of CCPC adoption among physicians over the last few years. On average, mean personal income tax savings for incorporated physicians are 4-5\%. The average incorporated GP with a family income of $\$ 272 \mathrm{~K}$ can realize an annual retained earnings of at least $\$ 10 \mathrm{~K}$. CCPCs favour married physicians with spouses or adult children. Of course, tax savings are largest for higher-income physicians. They also note that physicians who are paid a salary from their employer cannot in general benefit from a CCPC, an area of potential liability currently for both physicians and employers.

\section{All must deal with the real limits of government spending in a collective fashion...}

\section{Considerations to Overcome the Common Property Challenge and Improve Accountability}

Unlike most private sector budgets, physician service budgets are determined by politicians, not by market procedures. This reality was characterized as analogous to a "common property problem" by Hurley and colleagues some time ago (Hurley et al. 1997). Because the physician expenditure budget is a shared asset with provincial government and with physicians, both parties and the tax-paying public have skin in the game. All must deal with the real limits of government spending in a collective fashion that allows for an affordable budget consistent with fiscal capacity and that, at the same time, provides fair and reasonable compensation among the different practice groups represented by their association. Income discrepancies between proceduralists and the cognate professionals remain dramatic and invite a serious re-look at resource-based relative value fee scaling with fair economic value and distributive justice in mind. A quick glance at the Ontario data yields a dramatic contrast (Henry et al. 2012).

Ontario developed a robust resourcebased relative value schedule approach to establish fair fee settings via a special commission chaired by John Wade, former dean of medicine in Manitoba. The commission started in 1997 and produced its full report in 2002 (RBRVS 2002). It took several years to deliver recommendations, and, ultimately, they were largely ignored. Perhaps the spirit of the recommendations was entertained, but the general response from organized medicine at the time was not compelling.

Ironically, CMS in the US (Centers for Medicare and Medicaid Services) has routinely used a resource-based relative value scale since 1992 to deal with reimbursement. It is not without controversy itself, particularly in the relatively lower payments afforded to primary care doctors as well as the role of the AMA (Poses 2008) 
in recommending updates to the scale. Is there any appetite to revisit relative value in Canada with real attention to the health economic value of procedures? There are certainly enormous changes in technology affecting treatments and their value; might we consider new tables/entities/processes to hammer out some of the value distortions that continuously evolve in fee structures? Can we not address these vexatious issues with skilled professional health executive leaders working with direction from the government and organized medicine, working toward a common objective on relative value fee pricing? Some assert that physicians having a genuine measure of accountability in the place where they work would underpin better physician integration and clinical governance (Dobrow et al. 2008). As Mintz (2018) has fairly said in his commentary, it is not physicians who create the challenge, but greater physician accountability to patients and to the organizations where physicians work is possible.

We can either retool our institutional arrangements to ensure a more sophistical and continuous professionally led negotiation between health sector leaders representing provincial jurisdictions and their medical associations within an articulated fiscal framework, managed growth targets and relative value in mind or face a continuous, vexatious process that may not serve the interests of the profession or the publics represented by our governments.

A final consideration in linking physician payment and performance may be through statute and regulation (Sullivan and Brown 2014). Ontario's Excellent Care for All Act (2010) has given birth to an important link between quality measurement and improvement, payment and the public reporting of quality performance. In the initial steps, hospital chief executives (not all of whom are doctors) have been held to account for targeted improvements in quality.
These activities are captured and reported through Health Quality Ontario (HQO) through the quality improvement program (QIP), and hospital chief executives, or chief executives with their senior management, share modest reimbursement risk according to how well they perform on quality and safety targets, which are posted publicly and accessible on public hospital and HQO websites. A key issue here is that the risk is modest but tangible and may not require new investments to create modest performance-based risk. To the extent that this practice can be extended to legal entities in primary care, specialty and group practices, home and long-term care and other health sector entities with legal personality, progress is possible. Ontario has the levers to accelerate comparative quality reporting to occur among physician practices and set a standard for doing it with a public measure of accountability.

\section{References}

Boyle, T. 2017. "Ontario's Medical Regulator Cracking Down on Doctors Over 'Offensive' Cyberbullying." Toronto Star (November 30). Retrieved July 17, 2018. <https://www.thestar.com/news/gta/2017/11/30/ ontarios-medical-regulator-cracking-down-ondoctors-over-offensive-cyberbullying.html > .

Boyle. T. 2018. "Appeal Court Ends Secrecy of Payments to Ontario's Top-Billing Doctors." Toronto Star (August 3). Retrieved August 3, 2018. <https:// www.thestar.com/news/gta/2018/08/03/appeal-courtends-secrecy-of-public-payments-to-mds.html>.

Canadian Institute for Health Information (CIHI). 2016. Physicians in Canada. Retrieved July 17, 2018. $<$ https://www.cihi.ca/en/physicians-in-canada .

Canadian Institute for Health Information (CIHI). 2017. National Health Expenditure Trends, 1975-2017. Retrieved July 17, 2018. <https://www.cihi.ca/sites/ default/files/document/nhex2017-trends-report-en.pdf>.

Canadian Medical Association (CMA). 2018. "Basic Physician Facts." Retrieved July 17, 2018. < https:// www.cma.ca/En/Pages/basic-physician-facts.aspx>.

Canadian Nurses Association (CNA). 2012. 2010 Workforce Profile of Nurse Practitioners in Canada. Retrieved July 17, 2018. <https://www.cna-aiic.ca/-/media/cna/ page-content/pdf-en/2010_np_profiles_e.pdf>. 
CanadianPA.CA. n.d. Your Guide to the Canadian Physician Assistant Profession. Retrieved July 17, 2018. $<$ http://canadianpa.ca/ontario-pa-newgrads $>$.

Chatwood, S. 2018. "Building on Primary Care Reforms and Indigenous Self-Determination in the Northwest Territories: Physician Accountability and Performance in Context." Healthcare Papers 17(4): 70-76. doi:10.12927/hcpap.2018.25573.

Church, J., R. Skrypnek and N. Smith. 2018. "Improving Physician Accountability through Primary Care Reform in Alberta." Healthcare Papers 17(4): 48-55. doi:10.12927/hcpap.2018.25576.

Commonwealth Fund. 2017. 2017 Commonwealth Fund International Health Policy Survey of Older Adults. Retrieved July 17, 2018. <http://www. commonwealthfund.org/publications/surveys/2017/ nov/2017-commonwealth-fund-international-healthpolicy-survey-older>.

Dobrow, M.J., T. Sullivan and C. Sawka. 2008. "Shifting Clinical Accountability and the Pursuit of Quality: Aligning Clinical and Administrative Approaches." Healthcare Management Forum 21(3): 6-12. doi:10.1016/s0840-4704(10)60269-4.

Glazier, R.H. and T. Kiran. 2018. "Doctors and Canadian Medicare: Improving System Performance Requires System Change." Healthcare Papers 17(4): 41-47. doi:10.12927/hcpap.2018.25577.

Grant, H. and J. Hurley. 2013. "Unhealthy Pressure: How Physician Pay Demands Put the Squeeze on Provincial Health Care Budgets." University of Calgary School of Public Policy Research Papers 6(22). Retrieved July 17, 2018. <https://www.policyschool. ca/wp-content/uploads/2016/03/grant-physicianincome.pdf $>$.

Henry, D.A., S.E. Schultz, R.H. Glazier, R.S. Bhatia, I.A. Dhalla and A. Laupacis. 2012. Payments to Ontario Physicians from Ministry of Health and Long-Term Care Sources, 1992/93 to 2009/10. Retrieved July 17, 2018. <https://www.ices. on.ca/Publications/Atlases-and-Reports/2012/ Payments-to-Ontario-Physicians>.

Hurley J., J. Lomas and L. Goldsmith. 1997. "Physician Responses to Global Physican Expenditure Budgets in Canada: A Common Property Perspective.” Milbank Quarterly 75(3): 343-64.

Laporte, A. 2018. "Physician Service Costs: Is There Blame to Share Around?.” Healthcare Papers 14(4): 28-31. doi:10.12927/hcpap.2018.25579.

Leatt, P., G.H. Pink and M. Guerriere. 2000.

"Towards a Canadian Model of Integrated Healthcare." Healthcare Papers 1(2): 13-35. doi:10.12927/hcpap.17216.
Lomas, J., C. Fooks, T. Rice and R.J. Labelle. 1989. "Paying Physicians in Canada: Minding our Ps and Qs." Health Affairs 8(1): 80-102.

Marchildon, G.P. and M. Sherar. 2018. "Doctors and Canadian Medicare: Improving Accountability and Performance." Healthcare Papers 17(4): 14-26. doi:10.12927/hcpap.2018.25580.

McIntosh, T. 2018. "From Autonomous Gatekeepers to System Stewards: Can the Alberta Agreement Change the Role of Physicians in Canadian Medicare?" Healthcare Papers 17(4): 56-62. doi:10.12927/hcpap.2018.25575.

Mintz, J.M. 2018. "Canada's Ailing Health Care System: It's the Doctors' Fault?" Healthcare Papers 17(4): 63-69. doi:10.12927/hcpap.2018.25574.

Nielsen, L. and A. Sweetman. 2018. "Measuring Physicians' Incomes with a Focus on CanadianControlled Private Corporations." Healthcare Papers 17(4): 77-86. doi:10.12927/hcpap.2018.25572.

Poses, R. 2008. "More on Physician Reimbursement, CMS, the AMA's RVS Update Committee (RUC)." The Health Care Blog. Retrieved July 17, 2018. <http:// thehealthcareblog.com/blog/2008/05/12/more-onphysician-reimbursement-cms-the-amas-rvs-updatecommittee-ruc/>.

Resource-Based Relative Value Schedule Commission of Ontario (RBRVS). 2002. RBRVS Commission of Ontario Report to the Ontario Medical Association and Ontario Ministry of Health and Long-Term Care. Retrieved July 17, 2018. <http://www.ontla.on.ca/ library/repository/mon/4000/10305931.pdf >.

Rosenberg, L. 2018. "Healthcare Delivery and Physician Accountability in Quebec: A System Ready for Change." Healthcare Papers 14(4): 32-40. doi:10.12927/hcpap.2018.25578.

Sackett, D.L., W.O. Spitzer, M. Gent and R.S. Roberts. 1974. "The Burlington Randomized Trial of the Nurse Practitioner: Health Outcomes of Patients." Annals of Internal Medicine 80(2): 137-42.

Smith, A. 1776. The Wealth of Nations. London, UK: W. Strahan and T. Cadell.

Smith, A. 1795. Theory of Moral Sentiments. Cambridge, UK: Cambridge University Press.

Spitzer, W.O., D.L. Sackett, J.C. Sibley, R.S. Roberts, M. Gent, D.J. Kergin, et al. 1974. "The Burlington Randomized Trial of the Nurse Practitioner." New England Journal of Medicine 290: 251-56.

Sullivan, T. and A. Brown. 2014. "Inching Towards Accountability for Quality: Early Days for the Excellent Care for All Act." Healthcare Management Forum 27(2): 56-59. doi:10.1016/j.hcmf. 2014.03.010. 